\title{
Opinions about science and faith amongst Southern African clergy and theologians from the Reformed church tradition
}

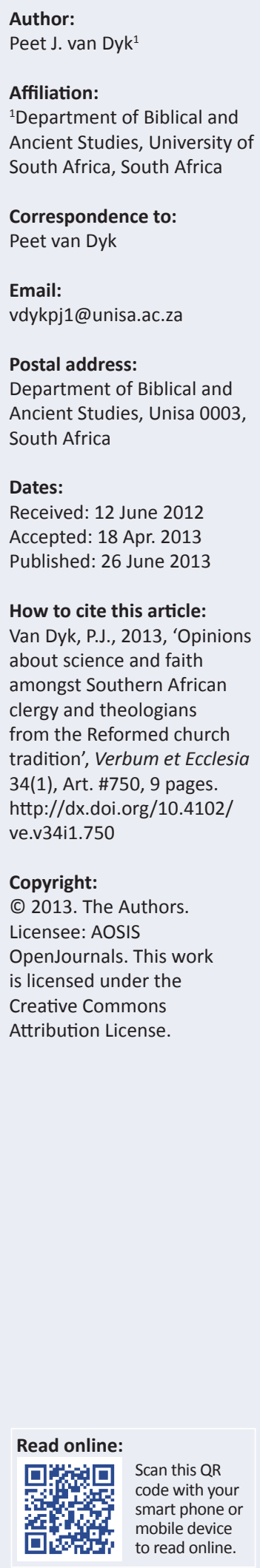

The main objective was to determine the opinions of Southern African clergy and theologians (from the Reformed church tradition) about science and faith. A secondary objective was to do an initial exploration amongst other church denominations. A total of 1770 structured electronic questionnaires were sent out via Email to all clergy belonging to the 'Nederduitse Gereformeerde' and 'Nederduitsche Hervormde' churches of which 108 were received back. The SPSS 20 statistical program was used to analyse the data. Most participants expressed a positive opinion about science. This positive opinion was closely linked to the general conviction that science and faith are not hostile towards each other, that science and faith can be reconciled and that the cosmos shows clear signs of divine intelligent design. Most participants nominally expressed strong anti-fundamentalist views regarding the authority of the Bible, but they did not necessarily appreciate the full implications of such a view, that is, given the prescientific cosmology of the Bible, it is highly unlikely that the biblical and scientific views of the natural world would be compatible. In conclusion, one could say that most participants were positively inclined towards science but arguably for the wrong reasons.

\section{Introduction and aims}

From the earliest developments of the so-called scientific method during the RenaissanceEnlightenment period, dissident voices raised concerns about some of the claims made by science. On the one hand, science was proclaimed as the new saviour that would rid humanity from superstition, false beliefs and the tyranny of the church. By the rigorous application of rationality, the testing of long-held beliefs and controlled observation and experimentation and the deliberate exclusion of supernatural causes as explanations of the natural world, the scientific method was set for unprecedented success (cf. Gadamer 1989:273; Gay 1966:34). On the other hand, the church censured the proto-scientific views of people like Copernicus and Galileo and later, with the start of the scientific revolution proper, a scientist such as Robert Boyle was vigorously opposed by Thomas Hobbes, who expressed serious doubt if the scientific method was an appropriate method to gain genuine knowledge (cf. Shapiro 2009:190-191).

Although Jean-Jacques Rousseau held scientists such as René Descartes and Isaac Newton in high regard and was not overtly hostile towards science, he nonetheless warned against the possible corruption of virtue and morality with the introduction of science (Jones 2000:213).

Since the time of Rousseau, the scientific method has variously been criticised by the 'counterenlightenment' of Romanticism - finding supporters from both left-wing and right-wing antiscience movements - and from fundamentalist religious circles. Current anti-science sentiments are also most often expressed by fundamentalist religious groups such as the creationist and the intelligent-design groups (Hill 2012:n.p.; Miller, Scott \& Okamoto 2006:765-766; Moran 2011:n.p.). This debate led to what Richard Dawkins (2006:11-19, 2009:4-5) views as a growing worldwide hostility and devaluation of science in general and the natural sciences specifically. It is especially the scientific 'theory' of biological evolution which has been chosen for the most severe criticism.

Another attack on science comes from more extreme postmodernist scholars (Friedlander n.d.:n.p.; Xenos n.d.). Most of the criticism from postmodernist scholars against science is directed against the search for absolute and objective truths as attempted by Cartesian modernity and against the excesses and reductionism of logical positivism (Nürnberg 2010b:93; Stiver 2010:127). Some extreme postmodernists go even further by declaring science nothing more than a form of 'cultural prejudice', 'invented by the current elite to maintain power' (cf. Friedlander n.d.:n.p.). An interesting side-effect of this kind of extreme postmodernism is its analogous critique on atheism (Thomas 2010:207). 
Although one should applaud the criticism of postmodernist scholars directed against the excessively arrogant claims by some scientists about science's rendering of purportedly universal truths and its absolute objectivity, one should also ask whether they are not attacking the proverbial straw doll. Today it is accepted by most scientists that absolute objectivity (as expected by modernity) is an unreachable ideal (Stiver 2010:127). Science is not perfect, and no serious scientist has ever doubted this. Scientists expect that 'some of their beliefs will be corrected, some confirmed, and some reframed in quite a different way' (Stiver 2010:127). This realisation is exactly why the scientific method has been devised: to test and re-test assumptions. This element of 'uncertainty' is, however, no reason for scientists to completely give up on science, to doubt reality or to think that all knowledge will be radically overturned - as assumed by relativist scholars (Stiver 2010:127). This modesty of science and the acknowledgement of its limitations should therefore not be seen as its Achilles heel - or as a reason to doubt its basic assumptions or methodology - but rather as a sign of its strength (Stiver 2010:127).

In Southern Africa, young-earth creationism, intelligent design and anti-science sentiments amongst some postmodernist academics have also become prevalent. This fact has become obvious to many biblical scholars who are regularly been called upon to confirm young-earth creationism or may have been challenged by fellow biblical scholars 'to make fun at' science and scientists (personal observations). Such encounters have caused a growing concern amongst some biblical scholars about the way in which science is being devaluated in some circles - begging the question to what extent 'science-bashing' has also become part of the Southern African scenario.

The main objective of this study was to determine the opinions of Southern African clergy and theologians from the Reformed church tradition about science, and how they relate science to faith. It also tried to determine possible intergroup differences in such opinions. (Although the ethnicity and gender of participants were determined during the survey, the limited nature of the sample did not allow for the exploration of possible differences between gender and ethnic groups.)

A secondary objective of the survey was to do an initial exploration of opinions amongst other Church denominations (outside the Reformed tradition). The purpose of this survey was to determine the feasibility of doing a more extensive survey amongst clergy and theologians from other denominations in Southern Africa later.

\section{Method}

For the purposes of this study, a survey was conducted amongst Southern African clergy and theologians by using an electronic questionnaire that was sent to 1770 Southern African clergy and theologians (i.e. in South Africa, Namibia and Zimbabwe). The choice of participants was determined by both the primary objective of the study (to assess opinions amongst clergy and theologians in the Reformed church tradition) and the secondary objective (to do a preliminary exploration amongst other church traditions). The sample was further influenced by the availability to the researcher of Email addresses.

The sample should therefore be viewed as a 'convenient sample' (cf. Coolican 2004:42) because it was not representative of all church denominations and excluded all clergy without Email addresses. Sampling attempted to avoid any bias in terms of gender, age, occupation or geographic location, but due to the nature of the population sampled, the results reflect mostly the views of White Afrikaans-speaking males from the Reformed church tradition in Southern Africa.

A total of 108 participants returned questionnaires (mostly from the Reformed tradition), representing a return rate of $6.1 \%$, which is comparable to what can be expected in such a survey and was sufficiently large to yield significant statistical results.

The following information was obtained from the questionnaire:

- It rendered demographical information (i.e. gender, ethnic group, age, highest theological qualification, where the qualification was obtained, church tradition, place of residence, occupation and discipline of specialisation or main interest).

- A total of 30 5-point Likert-type questions were used to measure participants' opinions regarding faith, science and evolution. The Likert-scale items were coded to range from +2 (strongly agree) to -2 (strongly disagree). This implies that a positive value on the scale indicated agreement with a specific statement, a zero value reflected uncertainty, whilst a negative value reflected disagreement.

By using the results from Principle Component Analysis (PCA), a science-faith-scale was constructed by using thirteen items from the questionnaire (cf. Appendix A for a complete discussion of statistical methods used).

\section{Results}

The demographic attributes of the 108 participants (who sent back questionnaires) are summarised in Appendix B, Table 1. Most of the participants were White males from the Reformed tradition and were older than 40 years. Just over $24 \%$ of the participants had doctoral degrees and most (85\%) were clergy, whilst the other $15 \%$ were lecturers at tertiary institutions.

\section{Science-faith scale}

The mean score for the calculated science-faith scale was +0.65 (out of a maximum score of +2 ). This mean score suggests a low to medium level of agreement with the scale but with a relatively large variation in opinions, as is illustrated by the high standard deviation ( $\mathrm{SD}=0.55$ ) and the large variation in opinions (minimum score: -1.46 ; maximum: +1.69 ). 
The mean score of +0.65 on the science-faith-scale suggests that, on average, the participants expressed positive opinions about science because science was seen as 'ultimately compatible' with the Bible and faith. This interpretation is supported by the reaction to individual questions, which reflected the general conviction of participants that science and faith are:

- not hostile to each other (cf. Question 1 below)

- that it is NOT difficult to reconcile faith and science (Question 3)

- that science and faith can be reconciled on some higher level (Question 5).

It is interesting to note that there were significant differences $(p<0.05)$ between lecturers and clergy in terms of their opinions about science and faith: Although both lecturers and clergy were basically positively inclined towards science, and both were convinced about its compatibility with faith, the mean score for lecturers on the scale was much lower $(+0.31)$ than those for clergy $(+0.71)$. Further analysis showed that it was mostly the lecturers in Old and New Testament who had significantly lower levels of agreement $(+0.20)$ than the rest of the participants. (See Appendix B, Table 2 for a summary of statistical data.)

These two significant differences suggest that lecturers in general (and more specifically, Old and New Testament lecturers) were much less convinced that science and faith are so easily reconcilable. This lower score for lecturers on the science-faith scale probably does not suggest a negative opinion about science as such but apparently a bigger awareness of the potential problems when trying to reconcile science and faith (see e.g. Dawkins 2006:11-19, who raises this confounded issue of the compatibility between science and faith in much more detail). This interpretation of the results is supported by the fact that lecturers were also less convinced than ordinary clergy that science and faith are compatible at some higher level (cf. Question 3 below) whilst questions which measured positive opinions about science, irrespective of faith (i.e. Questions 10 and 13), showed no differences between lecturers and clergy.

No significant differences on the science-faith scale $(p=0.85)$ were found between participants from the Reformed tradition and members of other denominations. Different ages or qualification levels also did not correlate significantly with opinions about science and faith.

The general results for the science-faith scale can be qualified and explained further by analysing the reactions to the specific questions in the questionnaire, as discussed below.

\section{Results for individual questions}

\section{Question 1: Science is hostile towards faith}

By far the majority of the participants (76.9\%) disagreed with the statement that science is hostile towards faith whilst only $23.1 \%$ agreed with the statement (see Appendix B, Table 3 for a summary of all frequencies and levels of agreement). On average, the participants displayed a medium level of disagreement (-0.77). This result suggests that most participants thought that science and faith are not necessarily hostile or contradictory to each other, implying that they may be compatible on some higher level (see Question 5 below).

Participants from the Reformed tradition disagreed more strongly with the statement than participants from other denominations. ${ }^{1}$ This result indicates that participants from the Reformed tradition were more convinced that science and faith are NOT necessarily hostile towards each other whilst members of other denominations may have been more aware of the potential incompatibilities between science and faith. However, due to the small number of participants from other denominations, one should be cautious about drawing conclusions from this difference because it warrants more indepth exploration.

\section{Question 2: Science and faith are important in different domains}

As is common amongst theologians, most participants (93.5\%) agreed with the fideist view that science and faith are both important but in different domains (cf. Hallanger 2010:167). On average, the participants expressed a high level of agreement $(+1.4$ out of a maximum of +2$)$ with the statement.

This question correlated with Questions 4 and 7 (see Appendix B, Table 4 for a summary of correlations), which assessed fundamentalist opinions amongst the participants regarding the Bible's authority in the field of natural science (cf. Grudem 1994:90 for a discussion on fundamentalist views). Question 2 was linked to non-fundamentalist views as is illustrated by the negative correlation with Question 4 (the Bible's authority depends on its literal and scientific accuracy) and the positive correlation with Question 7 (the Bible is not a science text book). These correlations suggest a logical consistency in the views of most participants, which can be phrased as follows: 'If the Bible is not authoritative in the field of natural science, it can only be authoritative in a different domain.'

Question 2 also correlated negatively with Question 3 (science and faith are difficult to reconcile) and positively with Question 8 (science education eradicates false beliefs and superstitions). These correlations suggest that some of the logical implications of placing faith and science in different domains (as suggested by Question 2) were not appreciated by all the participants. The term 'domain' usually refers to an independent territory or field (with its own set of laws or rules) which are therefore not necessarily compatible with those of other domains (cf. The Free Dictionary, n.p). Understood in this way, it is unlikely that different domains could easily be reconciled (as suggested by the negative correlation with Question 3) or that one domain (science) could be used to correct another domain (beliefs or faith) (as suggested by the positive correlation with Question 8).

1.Please note: whenever it is reported that two groups differed in their opinions, it is implied that this difference is statistically significant on the $p=0.05$ level. See Appendix B, Table 5 for statistical data on intergroup differences. 
The fact that most participants agreed with the fideist statement in Question 2 (that science and faith belong to different domains) does therefore not necessarily suggest that they fully appreciated the logical implications of such a view.

\section{Question 3: Science and faith are difficult to reconcile}

The fact that $89.8 \%$ of the participants disagreed with the statement, with a medium level of disagreement (mean $=-1.22$ ), suggests that most participants were fairly sure that science and faith are NOT difficult to reconcile. This suggests, as mentioned above, that many participants were positively inclined towards science because they were convinced that science and faith could be reconciled on some higher level. The question, whether participants would still be so positively inclined towards science if they believed that science and faith were contradictory, is therefore worthwhile investigating. The results for Question 6 may suggest that this may not necessarily be the case (see discussion below).

\section{Question 4: The Bible's authority depends on its scientific/literal accuracy}

This statement drew almost universal disagreement with $91.7 \%$ of the participants disagreeing and with a high level of disagreement $($ mean $=-1.49)$. This result suggests that most of the participants, at least nominally (see question 7 below), held strong non-fundamentalist views about the Bible's authority because they did NOT think that the Bible's authority depends on its literal or scientific accuracy as is typical in fundamentalist circles (cf. Grudem 1994:90).

\section{Question 5: Scientific and biblical accounts of creation are compatible on a higher level}

An $83.3 \%$ agreement with this statement at a medium level of agreement $($ mean $=0.88$ ) suggests that most participants were convinced that the biblical and scientific accounts of creation are somehow compatible and therefore not necessarily contradictory. As already suggested under Question 2, this view is not fully consistent with the nonfundamentalist views expressed in Questions 4 and 7 or the agreement with the view that the Bible and science belong to different domains (Question 2), but it is consistent with the views expressed in Question 1 and 3, which reckoned with a non-hostile relationship and the possibility of a reconciliation between science and faith.

\section{Question 6: If one MUST choose between science and faith, I will choose science}

Opinions about this statement were almost equally distributed between 'agree' (38.9\%), 'unsure' (31.5\%) and 'disagree' (29.6\%), rendering a very low level of agreement (mean $=+0.10)$. The variance in choices and the high number of participants who chose 'unsure' (31.5\%) suggest that participants were unsure about their choices, probably because many thought that the statement was a false dichotomy between science and faith. Another reason why this question has yielded such a varied result may be the fact that participants interpreted the question in more than one possible way. For example, they may have agreed with the statement because they believed that the Bible is not a science text book (cf. Question 7 below) and that this belief may imply that science is more authoritative on issues of the natural world than the Bible. Alternatively they may have argued that the Bible and science are compatible on some higher level and that it therefore does not matter whether one chooses either science or faith because they are compatible anyway.

\section{Question 7: The Bible was not intended as a scientific text book}

Except for one participant, everyone (99.1\%) agreed with the statement that the Bible was never intended as a science text book. The very high level of agreement (mean $=+1.78$ ) and the fact that $81.5 \%$ of participants 'strongly agreed' with this often-repeated slogan further underscored the participants' strong non-fundamentalist views (also supported by the results for Question 4).

The result in the previous paragraph should however be interpreted in the light of the rest of the survey, and it should be asked whether the non-fundamentalist view expressed by participants is not only a nominal agreement with a wellknown slogan without realising the full implications of such a view. That this may indeed be the case is suggested by the logical inconsistency of participants' answer to this question and their other opinions about science and faith. If the Bible is not a science text book (and is therefore not to be taken literally on aspects of science and cosmology), it logically implies that the Bible and science should not be compatible with one another. This follows from the fact that, because of the Bible's pre-scientific cosmology (cf. Bultmann 1984:9; Gadamer 1989:273; Gay 1966:34; Van Dyk 2009:5-6), many of the Bible's facts about the natural world would necessarily be wrong and therefore irreconcilable with the scientific views about the origin and the way the cosmos functions.

If this implication was fully appreciated by the participants, they would not have agreed with statements suggesting that the Bible and science are compatible. However, the fact that most participants thought that the Bible and science are not difficult to reconcile (Question 2) and the positive correlation with Question 5 (science and the Bible are compatible) suggest that many participants did not appreciate this implication. Their agreement with the non-fundamentalist view - that the Bible is not a science text book - should therefore be interpreted as a nominal agreement only. Such a nominal agreement with non-fundamentalism, rather than an in-depth understanding of its logical implications, would explain why some participants, whilst paying lip service to non-fundamentalism, nonetheless believed that the Bible and science can be reconciled. It would also explain the reason why participants were generally positively inclined towards science, that is, they saw no discrepancy between science and faith. This linkage between the non-fundamentalist view of the Bible and the positive evaluation of science is illustrated by correlations between this question (Question 7) and 
Question 10 (without science no progress is possible) and the negative correlation between Question 7 and Question 13 (science is nothing more than hunches).

\section{Question 8: Science education is important to eradicate false beliefs and superstitions}

The majority of the participants (71.3\%) agreed with the statement although a sizeable number $(25.9 \%)$ also disagreed with it. On average, the participants expressed a medium level of agreement $($ mean $=+0.69$ ). During the Renaissance and Enlightenment in Western Europe, science was explicitly viewed as having a corrective function by eradicating false beliefs and superstitions (cf. Gay 1966:34). The mainly positive response on Question 8 by the participants suggests that this potentially corrective function of science was appreciated by most respondents although it would be difficult to explain how science could have a corrective function on mistaken beliefs if science and beliefs belong to different domains (cf. Question 2).

\section{Question 9: The cosmos shows clear signs of divine intelligent design}

A majority (87.0\%) of people agreed with this statement, and on average, the participants displayed a very high level of agreement (mean $=+1.40$ ). This positive agreement suggests that most participants were not knowledgeable about or did not agree with the extensive critique which has been levelled against this popular but controversial concept by natural scientists (cf. Dawkins 2009:7; Schroeder 2008:319; Van Dyk 2007:847-859; Waldrop 2011:325).

The most probable explanation is that most participants accepted in faith that the cosmos was divinely designed but failed to distinguish such a belief from the position taken by the proponents of intelligent design. These proponents apparently propose that such design is 'clearly visible', thus mistakenly suggesting that it is possible to forward scientific and rational arguments for such a divine design and that it (and the existence of God) could therefore be proven (cf. Dawkins 2006:75-110).

Lecturers (especially lecturers in Old and New Testament) agreed less strongly than the rest of the participants with the view that the cosmos shows clear signs of divine cosmic design. This suggests that lecturers (specifically Old and New Testament lecturers) may have been more aware of possible criticisms against intelligent design than the rest of the participants. However, the fact that lecturers on average still agreed, rather than disagreed, with the statement suggests that even lecturers were not sufficiently aware of the criticisms against intelligent design or alternatively did not agree with the critique forwarded by natural scientists against the idea.

\section{Question 10: No progress is possible without modern science}

Most (87.0\%) of the participants agreed with the statement with a medium level of agreement (mean $=+1.13)$. This question reflects a basic positive view of science, irrespective of faith considerations (also see Question 13).

\section{Question 11: Science should be adapted to the faith perspective}

The opinions were extremely mixed on this statement with $50.9 \%$ of the participants agreeing with the statement whilst $39.8 \%$ disagreed. This mixed reaction is further illustrated by the close to zero average result (mean $=+0.15$ ) and the high standard deviation $(\mathrm{SD}=1.25)$. This result suggests that participants may have reacted differently depending on their interpretation of the question. In the light of the rest of the results, it is probable that those who interpreted the statement as suggesting that science is faulty and should be corrected by faith disagreed with the statement. In contrast, those participants who interpreted the question as suggesting that science and faith are inherently compatible, but that this compatibility is not always obvious, may have agreed with the statement because they thought that, by interpreting science in a more faith-friendly way, one could expose this underlying compatibility.

\section{Question 12: Theologians should interpret the Bible to show its compatibility with science}

The assumption that the Bible and science are basically compatible and that theologians merely need to demonstrate this compatibility was shared by $75.9 \%$ of participants whilst $19.4 \%$ of participants disagreed. On average, the participants displayed a medium level of agreement with the statement (mean $=+0.69$ ), but they varied in their opinions as is illustrated by the high standard deviation $(\mathrm{SD}=1.06)$. This question was related to the previous one (Question 11) although it differed from it by not suggesting that science needs changing (adaptation) but the opposite, that is, that the Bible needs to be interpreted 'correctly' and that such a 'correct' interpretation would reveal faith's compatibility with science. The question therefore assumed that science and faith are basically compatible and that this only needs to be demonstrated by theologians (for similar sentiments see Nürnberg 2010b:92-112 and Schroeder 2008:319-330).

\section{Question 13: Scientific theories are mere hunches}

A high number of participants $(84.3 \%)$ disagreed with the statement, with a medium level of disagreement (mean $=-1.03$ ). Such a negative response or disagreement with the statement suggests a basically positive attitude towards science (irrespective of faith considerations - also see Question 10). It is a growing and popular misconception amongst people worldwide that scientific theories (especially the 'theory' of biological evolution) are just theories and that science are therefore nothing more than hunches. Various scholars (cf. Chandra Chronicles 2008:n.p.; Dawkins 2009:9-18) have strongly argued against this popular misconception about science. It should be emphasised that the provisional nature of all scientific findings and the close link between perspective and findings (as strongly argued by postmodernist scholars) are not sufficient reasons for devaluating science to 'mere hunches' - as is often done within creationist circles (cf. Dawkins 2009:3-18; Stiver 2010:127). 
Question 14: Science and faith are both reasoned-based and should therefore yield similar results

The results showed a divergence in views amongst the participants: $44.4 \%$ agreed with the statement whilst $43.5 \%$ disagreed and $12.0 \%$ were unsure, yielding a very low level of overall disagreement (mean $=-0.001)$ and a high standard deviation $(\mathrm{SD}=1.23)$. The divergent opinions of participants may be due to the fact that they have focussed on different parts of the statement, that is, either on the part that both faith and science are reason-based or, alternatively, on the possibility of science and faith yielding similar results.

\section{Conclusion}

The results from the survey amongst Southern African clergy and theologians (mostly from the Reform tradition) can be summarised as follows:

- The science-faith scale suggests that most participants (primarily from the Reformed Christian tradition in Southern Africa) have a positive opinion about science because they think that science and faith are basically compatible at some level.

- Most participants expressed a positive opinion about science (irrespective of faith considerations) as is suggested by the fact that they largely agreed with the statement that no progress would be possible without science (Question 10) and by disagreeing with the statement that scientific theories were mere hunches (Question 13). This view is contrary to the negative opinions and even hostility expressed towards science in especially creationist circles in the USA.

- The interpretation of the results for the science-faith scale in the previous bullet is supported by the fact that most participants were convinced that science and faith are not hostile towards each other (Question 1), that science and faith can be reconciled (Question 3), that the biblical and scientific versions of creation are compatible at some higher level (Question 5), that the cosmos shows clear signs of divine intelligent design and that, when science and the Bible are interpreted 'correctly', their compatibility will become clear (Questions 11 and 12). These assumptions of Southern African clergy and theologians (i.e. that science and faith are compatible) are by no way unique but are relatively common amongst theologians and even amongst some natural scientists worldwide (cf. Krauss \& Dawkins 2007:n.p.; Mayer 2011:58-76; Nürnberg 2010a:127-148; Nürnberg 2010b:92-112; Schroeder 2008:319-330).

- Most participants nominally agreed with nonfundamentalist views regarding the authority and nature of the Bible (cf. Questions 4 and 7). The full logical implications of such non-fundamentalist views were, however, not appreciated by many of the participants as is suggested by the fact that these views correlated with views that the Bible and science are compatible, which would be unlikely if the Bible is not a science text book, if the Bible's authority does not depend on its literal and scientific accuracy and if the pre-scientific cosmology of the Bible is taken into account.
- Participants strongly agreed with the fideist view that science and faith occupy different domains (Question 2). It therefore appears that the popular fideist defence of faith against contradictory claims by science, by assigning them to different domains, is also common amongst Southern African theologians and clergy. This view is, however, not logically compatible with the generally expressed view by participants that science and faith are compatible, which is exactly what the concept of different domains wants to argue against.

- Most participants agreed with the idea that the cosmos shows clear signs of divine intelligent design and probably did not differentiate between accepting such divine design in faith versus the conviction that such divine design is 'clear' and can be proven.

In conclusion, one can say that Southern African clergy and theologians were in general positively inclined towards science (in contrast to the hostility against science often expressed in creationists circles in the USA) but arguably for the wrong reason, namely because they were convinced that science and faith are not contradictory and are ultimately compatible. This view is strongly contested by many natural scientists (cf. Dawkins 2006:11-19) and may be contrary to the self-declared purpose of the Renaissance and Enlightenment (cf. Gay 1966:34).

\section{Limitations and future research}

The fact that there was a difference in opinion between participants from the Reformed tradition and participants from other denominations regarding the possible hostility between science and faith (Question 1) may be an indication that a more extensive study amongst different denominations may yield interesting results and may yield interesting comparisons between different denominations.

It may also be interesting to determine in future whether the opinions about science and faith, as expressed by the mainly White male clergy and theologians from the Reformed tradition, are also generally shared by other ethnic groups and women within this church tradition.

Although the sample size of the survey was relatively small $(n=108)$, it was nonetheless large enough to yield statistically significant results with mostly small variations in opinions. These results indicate that the survey probably reflect the views of a noteworthy part of the clergy and theologians in the Reformed tradition although a larger sample size may have yielded greater generalisability.

\section{Acknowledgements Competing interests}

The author declares that he has no financial or personal relationship(s) that may have inappropriately influenced him in writing this article. 


\section{References}

Bultmann, R., 1984, New Testament and mythology and other basic writings, Fortress Press, Philadelphia.

Chandra Chronicles, 2007, 'It is not just a theory... It is a theory!', viewed 16 April 2012, from http://chandra.harvard.edu/chronicle/0308/theo/index.html

Coolican, H., 2004, Research methods and statistics in psychology, 4th edn., Hodder \& Stoughton, London. PMid:15094139

Dawkins, R., 2006, The God delusion, Bantam Press, London.

Dawkins, R., 2009, The greatest show on earth. The evidence for evolution, Bantam Press, London.

Friedlander, E.R., n.d., 'Why I am not a postmodernist', viewed 06 June 2012, from www.pathguy.com/postmod.htm

Gadamer, H.-G., 1989, Truth and method, 2nd edn., transl. J. Weinsheimer \& D.G. Marshall, Sheed \& Ward, London.

Gay, P., 1966, The Enlightenment: An interpretation. The rise of modern paganism, Weidenfeld \& Nicolson, London.

Grudem, W.A., 1994, Systematic theology: An introduction to biblical doctrine, Intervarsity Press, Leicester.

Hallanger, N.J., 2010, 'Reflecting on Kevin Sharpe, Taede Smedes, and the dialogue', Zygon 45(1), 165-176. http://dx.doi.org/10.1111/j.1467-9744.2010.01064.x

Hill, S., 2012, 'Ant-science agendas invade the schools; not just creationism anymore', viewed 06 June 2012, from skeptic.comdoubtful-news/anti-science-agendasinvade-the-schools-not-just-creationism-anymore/

Jones, R.H., 2000, Reductionism: Analysis and the fullness of reality, Bucknell University Press, Lewisburg.

Krauss, L.M. \& Dawkins, R., 2007, 'Should science speak to faith?', Scientific American 19 June, n.p.

Mayer, L., 2011, 'Integrating faith with learning in a postmodern age', Journal of Interdisciplinary Studies 24, 58-76.
Miller, J.D., Scott, E.C. \& Okamoto, S., 2006, 'Public acceptance of evolution', Science 313 (5788), 765-766. http://dx.doi.org/10.1126/science.1126746, PMid:16902112

Moran, L.A., 2011, 'Sandwalk. Strolling with a skeptical biochemist. Is creationism anti-science?', viewed 06 June 2012, from sandwalk.blogspot.com/2011/10/iscreationism-anti-science.html

Nürnberg, K., 2010a, 'Martin Luther's experiential theology as a model for faithscience relationships', Zygon 45(1), 127-148. http://dx.doi.org/10.1111/j.14679744.2010.01062.x

Nürnberg, K., 2010b, 'Becoming a scientist to the scientists: Theses on the relationship between natural science and Christian faith', Journal of Theology for Southern Africa 136, 92-112.

Pallant, J., 2007, SPSS survival manual. A step by step guide to data analysis using SPSS for Windows, 3rd edn., Open University Press, Berkshire.

Schroeder, B.C., 2008, 'Science instruction in the context of Christian faith', Theology and Science 6(3), 319-330. http://dx.doi.org/10.1080/14746700802206974

Shapiro, I., 2009, 'Reflections on Skinner and Petitt', Hobbes Studies 22, 185-191. http://dx.doi.org/10.1163/092158909X12452520755478

Stiver, D.R., 2010, 'A word about faith and science', Review and Expositor 107, 125128.

The Free Dictionary, n.d., 'domain', viewed 01 June 2012, from http://www. thefreedictionary .com/domain

Thomas, O.C., 2010, 'The atheist surge: Faith in science, secularism, and atheism', Theology and Science 8(2), 195-210. http://dx.doi. org/10.1080/14746701003675561

Van Dyk, P.J., 2007, 'So-called intelligent design in nature. A discussion with Richard Dawkins', Old Testament Essays 20(3), 847-859.

Van Dyk, P.J., 2009, 'Creation, temple and magic. A magico-mythical reading of Genesis 1', Old Testament Essays 22(2), 422-436.

Waldrop, M.M., 2011, 'Faith in science', Nature 470, 323-328. http://dx.doi. org/10.1038/470323a, PMid:21331019

Xenos, n.d., The postmodern critique on science, viewed 06 June 2012, from www. xenos.org/CLASSES/papers/postmosci.htm 


\section{Appendix A - Methodology Sampling}

Questionnaires were sent to all clergy (with Email addresses) in the 'Nederduitse Gereformeerde' and 'Nederduitsche Hervormde' churches (Email addresses of clergy from the 'Gereformeerde' and other Reformed traditions were not readily available on the internet). In addition, a small number of questionnaires were also sent to clergy and theologians in other denominations (e.g. the Evangelic Lutheran, Anglican and Methodist churches). Questionnaires were also sent to all theologians at the University of Pretoria, University of Stellenbosch, University of the Free State and members of the Old Testament Society of Southern Africa, irrespective of their denominations.

Participants were assured that their anonymity would be protected, and they were requested to either send back their completed questionnaires via an anonymous Email account or to ask a friend or colleague to send back the questionnaires on their behalf. This advice ensured that, even where participants sent back their questionnaires from their own Email accounts, the researcher could not be sure from which individual a questionnaire was received.

\section{Measuring instrument: Structured electronic questionnaire}

A structured electronic questionnaire (in MS Excel format) was used for the survey. With each question, the participants had to click on the answer of their choice. The electronic questionnaire was programmed in such a way that coding of choices was automatically transferred to a separate Excel sheet, which could then be copied error-free to the IBM Statistical Package for the Social Sciences (SPSS 20) for statistical analysis.

The questionnaire used Likert scales (ordinal five-point scales, ranging from 'strongly agree' to 'strongly disagree') to measure participants' opinions regarding (1) science and faith (14 questions) and (2) evolution and faith (16 questions). For the purpose of this article, only the 14 science and faith questions will be discussed.

Participants were explicitly instructed not to do any research regarding the questions or to discuss their choices with other people because the purpose of the survey was not to establish right or wrong answers but to assess clergy's and theologians' personal opinions and perceptions.

\section{Statistical analysis}

The IBM Statistical Package for the Social Sciences (SPSS 20) was used for descriptive and inferential statistical analysis of the data. For the sake of easier interpretation, the frequency of choices for the individual Likert-scale items were simplified by combining the 'strongly agree' with the 'agree' choices and the 'strongly disagree' with the 'disagree' choices. However, because this procedure could have hidden possible intergroup differences (where differences may be primarily between the 'agree' and 'strongly agree' or between the 'strongly disagree' and 'disagree' categories), levels of agreement or disagreement were also reported. This was achieved by first calculating the mean for each scale and then classifying this mean in terms of levels of agreement or disagreement as follows.

\section{Levels of agreement or disagreement:}

- High: \pm 1.33 to \pm 2.0 .

- Medium: \pm 0.66 to \pm 1.32 .

- Low: \pm 0.01 to \pm 0.65 .

A science-faith scale (consisting of 13 items) was constructed by using Principle Component Analysis. The scale was tested for reliability, and it returned a Cronbach-Alpha value of 0.752 , which is above the recommended minimum value of 0.7 (cf. Pallant 2007:98). The scale also yielded a nonsignificant result $(p=0.20)$ on the Kolmogorov-Smirnov test, indicating that the scale sufficiently adhered to normality to be used in parametric tests (e.g. the $t$-test) (Pallant 2007:62). To make the scale easier to interpret, the totals were divided by the 13 items to yield values between +2 and -2 .

To determine possible intergroup differences and correlations between individual Likert-scale items (questions), the nonparametric Mann-Whitney U test and Spearman correlations were used respectively. This was necessary due to their nonstandardised nature, the fact that individual items do not necessarily adhere to normality (in contrast to the Sciencefaith scale) and because they measured interval data (cf. Coolican 2004:363).

The level of significance was set at 0.05 , and only significant medium and high-strength correlations were reported. In the case of intergroup differences, only medium and high effect sizes were reported. 


\section{Appendix B - Results}

TABLE 1: Demographics of participants.

\begin{tabular}{|c|c|c|c|}
\hline Demographics & Characteristics & $\%$ & $n$ \\
\hline \multirow[t]{2}{*}{ Gender } & Male & 93.5 & 100 \\
\hline & Female & 6.5 & 7 \\
\hline Residence & City or big town & 78.7 & 85 \\
\hline \multirow[t]{2}{*}{ Age } & $>40$ years & 85.2 & 92 \\
\hline & $<40$ years & 14.8 & 16 \\
\hline \multirow[t]{2}{*}{ Ethnic group } & White & 94.4 & 102 \\
\hline & Other & 5.6 & 6 \\
\hline \multirow[t]{2}{*}{ Employment } & Clergy & 85.2 & 92 \\
\hline & Lecturers & 14.8 & 16 \\
\hline \multirow[t]{2}{*}{ Education Level } & $<$ Doctoral degree & 75.9 & 82 \\
\hline & Doctoral degree & 24.1 & 26 \\
\hline \multirow[t]{3}{*}{ Denominations } & Reformed tradition & 82.4 & 99 \\
\hline & Evangelic Lutheran & 9.3 & 10 \\
\hline & Other & 8.3 & 9 \\
\hline \multirow[t]{6}{*}{ Theological discipline } & New Testament & 9.3 & 10 \\
\hline & Missiology & 8.3 & 9 \\
\hline & Systematic Theology & 17.6 & 19 \\
\hline & Practical Theology & 40.7 & 44 \\
\hline & Ethics & 1.9 & 2 \\
\hline & Church History & 4.6 & 5 \\
\hline
\end{tabular}

TABLE 2: Intergroup differences on science-faith scale (means and $t$-test).

\begin{tabular}{|c|c|c|c|c|c|c|c|}
\hline Groups & Mean & SD & $n$ & $t$ & $d f$ & $p$ & Size effect \\
\hline Lecturers & 0.31 & 0.41 & 16 & 3.12 & 23 & 0.005 & Medium \\
\hline Clergy & 0.71 & 0.45 & 92 & & & & \\
\hline OT\&NT lecturers & 0.2 & 0.4 & 9 & -3.4 & 10.81 & 0.006 & Medium \\
\hline
\end{tabular}

TABLE 3: Frequencies and levels of agreement for questions.

\begin{tabular}{|c|c|c|c|c|c|c|}
\hline \multirow[t]{2}{*}{ Question } & \multicolumn{3}{|c|}{ Frequencies $(\%)$} & \multicolumn{3}{|c|}{ Level of agreement } \\
\hline & Agree & Uncertain & Disagree & Mean & SD & $n$ \\
\hline Question 1 & 21.1 & 0 & 76.9 & -0.77 & 1.13 & 108 \\
\hline Question 2 & 93.5 & 0 & 6.5 & +1.4 & 0.83 & 108 \\
\hline Question 4 & 91.7 & 0.9 & 7.4 & -1.49 & 0.88 & 108 \\
\hline Question 5 & 15.7 & 0.9 & 83.3 & +0.88 & 1.11 & 108 \\
\hline Question 6 & 29.6 & 31.5 & 38.9 & +0.10 & 1.27 & 108 \\
\hline Question 8 & 25.9 & 2.8 & 71.3 & +0.69 & 1.31 & 108 \\
\hline Question 9 & 8.3 & 4.6 & 87 & +1.40 & 0.92 & 108 \\
\hline Question 10 & 6.5 & 5.6 & 87 & +1.13 & 0.89 & 107 \\
\hline Question 11 & 39.8 & 9.3 & 50.9 & +0.15 & 1.25 & 108 \\
\hline Question 12 & 19.4 & 4.6 & 75.9 & +0.69 & 1.06 & 108 \\
\hline Question 13 & 84.3 & 9.3 & 6.5 & -1.03 & 0.81 & 108 \\
\hline Question 14 & 43.5 & 12 & 44.4 & -0.001 & 1.23 & 108 \\
\hline
\end{tabular}

TABLE 4: Correlations between questions (Spearman rho).

\begin{tabular}{|c|c|c|c|c|c|c|}
\hline Questions & 3 & 4 & 7 & 8 & 10 & 13 \\
\hline \multirow[t]{2}{*}{2} & rho $=-0.221$ & rho $=-0.226$ & rho $=+0.322$ & rho $=+0.274$ & - & - \\
\hline & $p=0.021$ & $p=0.019$ & $p=0.001$ & $p=0.004$ & - & - \\
\hline 5 & - & - & rho $=+0.196$ & - & - & - \\
\hline \multirow[t]{2}{*}{7} & - & - & - & - & rho $=+0.300$ & rho $=-0.302$ \\
\hline & - & - & - & - & $p=0.002$ & $p=0.001$ \\
\hline
\end{tabular}

TABLE 5: Intergroup differences for individual items (Mann-Witney U Tests).

\begin{tabular}{|c|c|c|c|c|c|c|c|c|c|}
\hline Question & Groups & Items & Mean & SD & $n$ & $U$ & Z & $p$ & $n$ \\
\hline \multirow[t]{2}{*}{1} & Denomination & Reformed & -0.88 & 1.07 & 89 & 621.0 & -1.974 & 0.048 & 108 \\
\hline & & Other & -0.26 & 1.28 & 19 & & & & \\
\hline \multirow[t]{4}{*}{9} & Occupation & Lecturer & +0.50 & 1.26 & 16 & 367.0 & -3.676 & 0.000 & 108 \\
\hline & & Clergy & +1.55 & 0.75 & 92 & & & & \\
\hline & & OT\&NT lecturers & +0.22 & 1.20 & 9 & 164.5 & -3.598 & 0.000 & 108 \\
\hline & & Others & +1.51 & 0.81 & 99 & & & & \\
\hline
\end{tabular}

